\title{
Linking Challenge Stress, Negative Affect, and Work Engagement: The Moderating Effect of Self-Compassion
}

\author{
Mr. Christophe RUKUNDO ${ }^{1}$, Dr Jean-Noel BEKA BE NGUEMA ${ }^{1}$, Miss Cynthia \\ Atamba $^{1}$, Miss Mohamed Habuba Halima ${ }^{1}$, Miss Akorfa Neku ${ }^{1}$
}

\begin{abstract}
${ }^{1}$ University of Science and Technology of China, No.96, JinZhai Road Baohe District, Hefei, Anhui, 230026, P.R. China. E-mail: chris3@mail.ustc.edu.cn
\end{abstract}

Received: Oct. 22, 2020 Accepted: Nov. 20, 2020 Online published: Nov. 30, 2020

doi:10.5296/ijhrs.v10i4.18007ＵRL: https://doi.org/10.5296/ijhrs.v10i4.18007

\begin{abstract}
Dealing with challenging stressors is unquestionably the cornerstone of work life. On the other hand, challenge stress alters employees' work engagement and makes them feel unsure of their ability to develop careers and perform well. In this study, we tested the mediating effects of negative affect on the negative relationship between challenge stress and work engagement. This relationship was moderated directly by self-compassion. Data from 137 employed professionals enrolled in the Executive MBA in one of the largest Chinese universities were used to test these relationships. Data analysis results show that challenge stress has a significant negative effect on work engagement while negative affect mediated this relationship. The relationship between challenge stressors, negative affect, and work engagement was directly and indirectly moderated by self-compassion. We finished by discussing the theoretical and practical implications.
\end{abstract}

Keywords: challenge stress, negative affect, self-compassion, work engagement, transactional stress theory

\section{Introduction}

With the world of work that is evolving so fast, many researchers and practitioners have focused on how various occupational stressors influence employees' work engagement levels. Occupational stressors are characteristics or events in the workplace that can influence employee work engagement (McGrath \& Beehr, 1990; O'Brien \& Beehr, 2019). Schaufeli and Bakker (2010) theorized work engagement as a positive, affective-motivational state of high energy, followed by high dedication and a strong motivation. Work engagement has 
been shown to coincide with high levels of creativity, task performance, organizational citizenship behavior, and client satisfaction. Furthermore, employees' engagement has been confirmed to improve productivity, reduce staff turnover, make more profits, and retain customers at a higher rate (Bakker \& Demerouti, 2014). However, studies have discovered that work engagement may also differ within persons - across time and situations. There have been limited studies examining when and how specific occupational stressors, such as challenge stressors, may influence work engagement.

Previous studies have revealed that employees are most engaged when experiencing challenge stressors as it provides them a variety of resources (Bakker \& Demerouti, 2014). Challenge stressors are explained as work-related demands or conditions that, though strain-provoking, might lead to high-performance opportunities and, thus, a strong sense of success if an individual can conquer the problematic situations they present. In the initial phases, facing challenging stressors may induce negative affect, e.g., anger, frustration, and guilt; however, in the long run, there is a sense of accomplishment accompanying high performance is missing (Webster et al., 2011). Typical challenge stressors comprise high job scope, responsibility, and time pressure (Cavanaugh et al., 2000).

Grounded in the transaction model of stress and coping (Ben-Zur, 2019), we posit that challenge stressors will negatively influence work engagement, and this relationship will be mediated by negative affect. The transactional theory of stress discusses the psychological mechanisms of appraisal and coping that enormously contribute to an individual's stress process. In line with the transaction stress story, work demands, or characteristics that employees tend to view as challenges are positively associated with work engagement (Crawford et al., 2010). There have been inconsistencies in the association between challenge stressors and negative affect. Studies have shown that managing challenge stressors may be motivating and trigger positive affect (Bennett et al., 2018; Tadić et al., 2015). Simultaneously, dealing with challenge stressors can also be effortful and increase strain and trigger negative affect (e.g., Ten Brummelhuis \& Bakker, 2012). Overall, there seems to be a reason to believe that challenge stressors will have differential effects on negative affect. Our primary focus is to study this relationship between challenge stressors and negative affect and propose a moderating mechanism.

The current study makes two contributions. First, this study examines the potential for within-person variation in negative affect during the appraisal of challenge stressors. Previous research has interchangeably focused on various occupational stressors without examining how appraisal of challenge stressors may impact negative affect and work engagement. Secondly, our current study builds on the transaction model stress and coping Ben-Zur (2019) proposed. We propose that self-compassion is a meaning-focused coping strategy that is viable to employees faced by challenge stressors. Self-compassion plays a vital role as underlying mechanisms explaining the relationships between challenge stressors, negative affect, and work engagement. Self-compassion is defined as the ability to be accommodating and sympathetic to oneself at times of mistake or misery (NEFF, 2003). Therefore, it is a vigorous way of relating to oneself that internalizes the compassion and support that may typically extend to a friend in times of need (Ferrari et al., 2019). 


\section{Theory and Hypothesis Development}

\section{The Transactional Model of Stress and Coping}

Employees have to deal with various challenge stressors in their work roles. Dealing with high job scope, responsibility, and time pressure leaves the employee feeling exhausted and may alter an employee's work engagement. This proposition is in line with Lazarus and Folkman's (1987) transaction stress theory that challenge stressors arise from demands that a person feels confident about mastering whatever he tries to do. These demands are aligned with emotional reactions. When an employee perceives that environmental or internal demands exceed their resources and evaluate their coping ability in response to the stressful event, this generates an emotional reaction.

The change in coping depends on individual appraisal when faced with a challenging stressor (Ben-Zur, 2019). His study posited that problem-focused and emotion-focused approaches were not viable in the face of challenge stressors as they required extra resources. Therefore, they proposed meaning-focused coping, whereby an individual draws on their beliefs, values, and existential to cope with challenging stressors. By introducing a focused coping approach, an individual identifies a self- growth in the face of challenge stressors and can generate positive emotions and restore coping resources to stay engaged in their work. These feelings allow continuous revision and development of new coping strategies to adapt effectively despite initial unsuccessful attempts (Hitchcock et al., 2015). Using the most updated transaction model of stress and coping from (Ben-Zur, 2019) as a framework, the current study tests the modulating direct and indirect effect of self-compassion on the relationship between challenge stress, negative effect, and work engagement.

\section{Challenge stress, negative affect, and work engagement}

Challenging stressors are perhaps inevitable in every working environment. Meta-analytical evidence shows that challenge stressors have both adverse effects and favorable effects on employees' motivation and performance (Bennett et al., 2018; Tadić et al., 2015). Thus, we suggest that exposure to challenge stressors might increase negative affect and reduce their work engagement. Managing challenge stressors may be strenuous to individuals who have to balance their work roles with others (Prem et al., 2017).

Referring to transactional model of stress and coping, challenge stressors provoke strain and deplete employees' psychological, emotional, and mental resources. To fulfill their work requirements, employees have to invest extra effort in their duties (Lepine et al., 2004). For instance, employees may be required to concentrate on only one task and find ways to resist distractions (Roseman et al., 1994). In instances where the challenge requires to work beyond their job scope, they are required to invest time to develop the new skills in addition to meeting their tight deadlines (Lepine et al., 2004). Therefore, the employees must draw on their self-regulatory resources (e.g., Prem et al., 2016; Rivkin et al., 2015) when faced with challenge stressors. Employees who cannot cope with challenge stressors will experience a sense of failure (Lepine et al., 2004), increasing their experience of negative affect and feeling less engaged in their work roles. Increased negative affect should further decrease 
creativity and development because it narrows employees' thought-action repertoire (Fredrickson, 2001). In sum, we hypothesize:

\section{Hypothesis 1: Challenge stress is negatively related to work engagement}

\section{Negative affect as a mediator}

Past theoretical and empirical work has examined the associations between affectivity and work-related outcomes (Deng et al., 2016), such as work engagement. According to (Schwarz \& Clore, 2006), people typically rely on their affect balance to form judgments of how (dis) contented they are with their work accomplishments. Prior research has confirmed a negative correlation between negative affect and work engagement (Schmitt et al., 2015), more so in the face of occupational stressors.

As challenge stressors emerge from individual perceptions of events, these perceptions may influence the experience of negative affect and work engagement (Extremera \& Rey, 2016). Accumulating research literature has confirmed the mediating role of negative affect between self-reported stressors and work engagement both in general and in organizational contexts (Bennett et al., 2018; Tadić et al., 2015). Challenges stressors highlight is regarded as strenuous, which increases negative affective responses (Parker et al., 2017). We, therefore, posit the following hypothesis:

Hypothesis 2: Negative affect mediates the relationship between challenge stress and work engagement.

\section{Moderating effect of self-compassion}

Challenging stressors are perhaps inevitable in every working environment. Meta-analytical evidence shows that challenge stressors have both adverse effects and favorable effects on motivation and performance (Bennett et al., 2018; Tadić et al., 2015). Therefore, we propose that exposure to challenge stressors might hold the potential for both positive and adverse effects on employees' negative affect and work engagement.

Coping with challenging stressors may be motivating and provide opportunities for personal growth and learning at work (Prem et al., 2017), which further reduces negative affect and positively affects employees' work engagement. Simultaneously, coping with challenging stressors can also be effortful and increase strain (e.g., Demerouti \& Bakker, 2007). Therefore, we propose an increase in negative affect and a reduction in work engagement. Overall, there seems to be a reason to believe that challenge stressors will have differential effects on employee negative affect and work engagement. It also highlights the potential for a moderating mechanism. We propose a self-compassion as a boundary condition in the relationship between challenge stress and negative affect.

Self-compassion has recently appeared as a construct of interest in applied psychology (Ferrari et al., 2019; Neff, 2011), driven by recognizing the connection between a tendency to be self-compassionate and employee well-being. Neff (2003) conceptualized self-compassion as the ability to be kind, connected to self, and be mindful of oneself. With that being said, self-compassion enables an individual to extend support to oneself, recognize that 
imperfection is part of the human condition, and approach negative emotions with equanimity. In organizational settings, a tendency to be self-compassionate has been linked with a range of outcomes, including work engagement (Kotera et al., 2020), burnout (Pérula-de Torres et al., 2019), and perceived organizational threat (Henshall et al., 2018).

Referring to the transactional model of stress and coping, it provides personal growth opportunities when employees find meaning in the face of challenging stressors. Previous research suggests that self-compassion might buffer the adverse effects of fear of failure, fear of negative evaluation, social comparison, and social anxiety (Vötter \& Schnell, 2019). Therefore, self-compassion might be particularly useful for evaluating stressors as a way of meaning-focused coping (Lazarus \& Folkman, 1987). Through meaning-focused coping, employees who are high in self-compassion will experience a sense of personal accomplishment when faced with challenging stressors (Lepine et al., 2004). In contrast, employees low in self-compassion will be immersed in self-criticism and negative affect, e.g., anxiety (Neff, 2011). An increase in negative affect will impede creativity and development because it narrows employees' thought-action repertoire (Fredrickson, 2001) and alters employees' work engagement. Thus, self-compassion promotes meaning-focused coping, which then reduces challenge stress and negative affect and results in greater work engagement. In sum, we hypothesize:

Hypothesis 3: Self-compassion moderates the relationship between challenge stress and negative affect.

Hypothesis 4: Self-compassion indirectly moderates the relationship between challenge stress and work engagement via negative affect.

\section{Aims and Objectives}

The existing study aims to contribute to the literature investigating the potential mechanisms underlying the associations between challenge stressors, negative affect, and work engagement. This study proposed four hypotheses to test these relationships. These hypotheses included: (1) challenge stress is positively connected to work engagement; (2) negative affect mediates the relationship between challenge stress and work engagement; (3) self-compassion directly moderates the relationship between challenge stress and negative affect; (4) Self-compassion indirectly moderates the relationship between challenge stress and work engagement.

\section{Participants}

The sample comprises 150 Executive MBA students from one of China's largest universities who voluntarily participated in the survey. These students worked on a full-time basis before enrolling in the university and are still working on a part-time basis (during weekends).

\section{Recruitment}

Survey takers were recruited by using students' network WeChat groups. WeChat is a popular social media application that was developed by Tencent. WeChat was launched in 2011. Similar to WhatsApp and Telegram, WeChat has changed into the most extensive stand-alone 
application in China.

\section{Sample Selection}

We collected data from working Executive MBA students enrolled in their studies on a part-time basis. We designated this sample for various reasons. First, working Executive MBA students emerge from a wide selection of organizations, which improved our generalizability findings. Second, previous studies have revealed that working MBA students share some common factors such as job level, social class, and relative income relevant to our study outcome. Third, working MBA students are eligible for being knowledgeable employees. Davenport $(2005 ; 19)$ stated that knowledge workers had higher education, expertise, or the primary purpose of their jobs involves the creation and experience, distribution, or application of knowledge compared to other workers. In this context, we assumed that knowledge workers were passionate about learning and development in their workplace and could flourish amidst challenging stressors. Also, previous research has shown that knowledge workers were susceptible to occupational stressors (Prem et al., 2017) and strived to be engaged in their work roles.

\section{Measurements}

Challenge stress: Challenge stress was measured with a six-item scale from LePine et al. (2004). The participants were asked to specify the extent to which the statements produced stress at work using scale ranging from 1 (no stress) to 7 (a great deal of stress). The sample items are "The number of projects/assignments in your workplace," "The difficulty of the work required in your workplace."

Negative affect: Negative affect was measured with a six-item scale adapted from (Keeping \& Levy, 2000) scale. The negative affect items were "agitated," "angry," "annoyed," "bothered," "disgusted," and "irritated." For this scale, employees responded in terms of how they felt at that moment, thus evaluating their current affective state. Responses were indicated on a 7-point scale from does not apply at all to applies very much.

Self-Compassion: Self-compassion was evaluated using the Self-Compassion Scale developed by Neff in 2003. This scale requires individuals to show their agreement on six items that assess three aspects of self-compassion; self-kindness, common humanity, and mindfulness. The sample items were "When I'm going through a tough time, I give myself the caring and tenderness I need," "When things are going badly for me, I see the difficulties as part of life that everyone goes through." The items were evaluated on a 7-point Likert-type response scale where $1=$ almost always and $7=$ rarely.

Work Engagement Scale: Work engagement was assessed with five items of the Utrecht Work Engagement Scale (UWES) developed by Schaufeli et al. (2002). Participants were asked to rate the engagement level when faced with a stressful work event but were bound to bring a sense of accomplishment. Sample items are "I feel strong and vigorous" and "I feel bursting with energy." All items were estimated on a 7-point scale ranging from 1 (does not apply) to 7 (fully applies). 
Control variables: Gender, age, and tenure were used as control variables in the statistical analyses.

\section{Research methodology}

\section{Procedure}

Before conducting this study, all measures were prepared following the national research committee of Chinese ethical standards and Helsinki's declaration. We obtained consent from all the respondents who participated in the study. The consent comprised of the following elements: the stated purpose of the study, a declaration regarding confidentiality and anonymity of our survey takers, and a declaration regarding the participant's right to withdraw and cancel their consent at any time they want. Web-based questionnaires were sent to all the participants to focus on those employees who met the study criteria. The study criteria state that the employees should have been worked at their current workplace for at least three months and worked with a minimum of forty hours a week (full-time employees) before the time of participating in the survey. After evaluating their eligibility, 13 members did not meet the sample screening criteria, leaving a sample of one hundred and thirty-seven participants. Of the 137 participants, sixty-seven percent were males and the rest being females; 29.70 years was the mean age of our participants $(S D=0.47)$ with an average tenure of 4.83 years $(S D=0.82)$.

\section{Data Analysis}

To examine the hypothesis that we established, we first used SPSS version 23.0 to conduct the hierarchical multiple regression to study the mediating effect of negative affect on the suggested independent variables and work engagement. Then we studied the moderating effect of self-compassion by using hierarchical multiple regression. We first put the control variables in Step 1, the independent variable in step 2, and the moderator in step 3. We calculated the mean for all the component variables required to establish the relationship between the variables, i.e., role conflict (challenge stress) and self-compassion (SEC). We then put the interacted variables (SEC x CS) in step 4. Lastly, we conducted our bias-corrected bootstrapping procedure in PROCESS macro, Model 8, to assess the moderated mediated model (Hayes, 2013).

\section{Results}

The mean $(\mathrm{M})$, standard deviation $(S D)$, and correlation for all variables are summarized in Table 1. Challenge stress (CS) was observed to be positively related to negative affect (NA) where $(\beta=.17, \mathrm{p}<.05)$. Furthermore, challenge stress was negatively related to work engagement (WE) where $(\beta=-.16, \mathrm{p}<.05)$. Negative affect fully mediated the relationship between challenge stress and work engagement $(\beta=0.33, p<0.05$; Table 2, Model 6$)$. Table 3 shows that the interaction between challenge stress and self-compassion was negatively correlated with employee work engagement $(\beta=0.10, p<0.05)$. The indirect effect of challenge stress on work engagement via negative affect was only significant for low and mean self-compassion levels. These are a depiction of the support of hypotheses 1, 2, 3, and 4 . The interaction plot illustrated in Figure 2 shows that self-compassion buffers employees 
from experience negative affect when faced with challenge stressors.

\section{Discussion}

The current study builds on prior work (Prem et al., 2017) to examine the interaction between challenge stress, negative affect on work engagement. Our results revealed that challenge stress negatively predicted work engagement, and negative affect fully mediated the relationship between challenge stress and work engagement. These results challenge the previous findings that show that challenge stressors are always associated with positive outcomes. Further, Barker et al. (2012) and Burger et al. (2017) demonstrated that challenge stress increases the risk of psychological problems after every adverse life event.

In line with the transactional stress theory (see: Susan Folkman, 1984), we found the relationship between challenge stress, negative affect, and work engagement depends on employees' self-compassion. In particular, the results propose that high levels of self-compassion buffer the outcome of challenge stress on employees' negative affect and work engagement. These findings imply that self-compassion plays an essential role in evaluating occupational stressors, promoting their work engagement. As challenges were previously seen to have both adverse and positive outcomes at work (Prem et al., 2017), our new outcomes make a vital contribution to the literature, allowing us to comprehend better how such interaction influences work engagement.

\section{Theoretical Implications}

This study contributed two significant theoretical contributions. First, our study solved the problem of the inconsistent findings around outcomes of challenge stress while utilzing the transactional model of stress and coping (See: Ben-Zur, 2019) as its framework. Specifically, we demonstrated that employees consider challenge stress a negative strain that negatively influences employees' work engagement. We also related challenge to general negative affect and explored its differential effects on employees' negative affect. Second, we tested the moderating role of self-compassion in alleviating the effect of challenge stress on negative affect and work engagement. Positive psychology literature has shown that harnessing positive emotions may reduce negative emotions (Fredrickson, 2001), thereby promoting work engagement. In sum, this present study's overall purpose was to build and test these associations to provide a coherent and meaningful contribution to the previous studies.

\section{Practical Implications}

Our findings provide additional evidence that challenge stress outcomes thwart employees' work engagement. Based on our results, employees always found coping mechanisms for both challenge stress and negative affect. When faced with challenging stressors, employees will often find meaning in them and thereby stay engaged in their work. However, previous research has highlighted that self-compassion is a trait (Halbesleben \& Wheeler, 2008). Leaders may institute intervention to harness self-compassion in the employees to enable them to face challenging stressors. Work engagement has a reverse causality such that engaged employees perform better than non-engaged employees because they often experience positive emotions such as happiness, enthusiasm, and joy (Fredrickson, 2001). 


\section{MInstitute ${ }_{\text {Mnk }}^{\text {Macrothink }}$}

International Journal of Human Resource Studies

ISSN 2162-3058

2020, Vol. 10, No. 4

They are also characterized by a high level of enthusiasm, experience better health, create their resource and their won job, and finally transfer their engagement to their fellow employees at work (Bakker \& Demerouti, 2008). This causality means that engaged employees are more tolerant of challenging stressors.

\section{Limitations and Future Directions}

Although we presented theoretical and practical implications of our findings, this study has certain limitations, which researchers may find as avenues for future studies. First, since the current study results were collected using a self-reported questionnaire, there is the possibility of common method bias known as CMB (Podsakoff et al., 2003). Thus, CMB may be a concern to address in future studies. Second, about our research design, our self-reported data were collected from a single source at one point in time, and we strongly encourage future studies to consider collecting data from different sources and timeframe. Third, since the current study used a cross-sectional design, we cannot assess real causal relationships. In future studies, we suggest using rigorous research designs, such as experimental or longitudinal designs, to facilitate causal inferences. Besides, the objective of our research is limited to work engagement. Future research might explore other possible outcomes that may result from this relationship. A call for future studies is to explore other possible organizational variables that may moderate and mediate the association between challenge stress, negative affect, and work engagement. Despite these limitations, our findings deliver evidence of the importance of self-compassion. The direct and direct effect of challenge stress on negative affect and work engagement hinges upon this moderator.

\section{Conclusion}

Based on a sample of 137 employed professionals enrolled in an Executive MBA in one of the Chinese largest universities, we have tested a moderated mediation model in which self-compassion directly and indirectly moderates the effect of challenge stress on negative affect and work engagement. Our findings reveal that the indirect effect is highest when self-compassion is high and lowest when self-compassion is low. This research exclusively examined challenge stressors since it has been shown to have both positive and negative outcomes at the workplace. The central message from these findings is that public organizations should encourage self-compassion in employees to enhance work engagement among their employees.

\section{Funding}

We received funds for this study from the block grants provided by the Chinese Government Scholarship.

\section{Acknowledgments}

My acknowledgments go to my supervisor from the Graduate School of Management at the University of Science and Technology of China, for his valuable suggestions and expertise in our study. 


\section{References}

Bakker, A. B., \& Demerouti, E. (2008). Towards a model of work engagement. Career Development International. https://doi.org/10.1108/13620430810870476

Bakker, A. B., \& Demerouti, E. (2014). Job Demands-Resources Theory. In Wellbeing. https://doi.org/10.1002/9781118539415.wbwell019

Barker, E. D., Copeland, W., Maughan, B., Jaffee, S. R., \& Uher, R. (2012). Relative impact of maternal depression and associated risk factors on offspring psychopathology. British Journal of Psychiatry. https://doi.org/10.1192/bjp.bp.111.092346

Ben-Zur, H. (2019). Transactional Model of Stress and Coping. In Encyclopedia of Personality and Individual Differences. https://doi.org/10.1007/978-3-319-28099-8_2128-1

Bennett, A. A., Bakker, A. B., \& Field, J. G. (2018). Recovery from the work-related effort: A meta-analysis. Journal of Organizational Behavior, 39(3), 262-275. https://doi.org/10.1002/job.2217

Burger, R., Posel, D., \& von Fintel, M. (2017). The relationship between negative household events and depressive symptoms: Evidence from South African longitudinal data. Journal of Affective Disorders. https://doi.org/10.1016/j.jad.2017.04.031

Cavanaugh, M. A., Boswell, W. R., Roehling, M. V., \& Boudreau, J. W. (2000). An empirical examination of self-reported work stress among U.S. managers. Journal of Applied Psychology, 85(1), 65-74. https://doi.org/10.1037/0021-9010.85.1.65

Crawford, E. R., LePine, J. A., \& Rich, B. L. (2010). Linking job demands and resources to employee engagement and burnout: A theoretical extension and meta-analytic test. Journal of Applied Psychology. https://doi.org/10.1037/a0019364

Davenport, H. T. (2005). Thinking for a living; How to get betterpPerformance and results from knowledge workers. Economist, 378(8461), 9-14. https://doi.org/10.1515/9783110289671

Demerouti, E., \& Bakker, A. B. (2007). The Oldenburg Burnout Inventory: A good alternative to measure burnout and engagement. Handbook of Stress and Burnout in Healthcare.

Deng, X., Ding, X., Cheng, C., \& Chou, H. M. (2016). Feeling Happy and Sad at the Same Time? Subcultural Differences in Experiencing Mixed Emotions between Han Chinese and Mongolian Chinese. Frontiers in Psychology, 7. https://doi.org/10.3389/fpsyg.2016.01692

Extremera, N., \& Rey, L. (2016). Ability emotional intelligence and life satisfaction: Positive and negative affect as mediators. Personality and Individual Differences, 102, 98-101. https://doi.org/10.1016/j.paid.2016.06.051

Ferrari, M., Hunt, C., Harrysunker, A., Abbott, M. J., Beath, A. P., \& Einstein, D. A. (2019). Self-Compassion Interventions and Psychosocial Outcomes: a Meta-Analysis of RCTs. Mindfulness, 10(8), 1455-1473. https://doi.org/10.1007/s12671-019-01134-6 


\section{Macrothink}

International Journal of Human Resource Studies

ISSN 2162-3058

2020, Vol. 10, No. 4

Folkman, S. (1984). Personal control and stress and coping processes: A theoretical analysis. Journal of Personality and Social Psychology. https://doi.org/10.1037/0022-3514.46.4.839

Fredrickson, B. L. (2001). The role of positive emotions in positive psychology: The broaden-and-build theory of positive emotions. American Psychologist, 56(3), 218-226. https://doi.org/10.1037/0003-066X.56.3.218

Halbesleben, J. R. B., \& Wheeler, A. R. (2008). The relative roles of engagement and embeddedness in predicting job performance and intention to leave. Work and Stress. https://doi.org/10.1080/02678370802383962

Hayes, F. A. (2013). An introduction to mediation, moderation, and conditional process analysis: A regression-based approach. NY: Guilford Press.

Henshall, L. E., Alexander, T., Molyneux, P., Gardiner, E., \& McLellan, A. (2018). The relationship between perceived organisational threat and compassion for others: Implications for the NHS. Clinical Psychology \& Psychotherapy, 25(2), 231-249. https://doi.org/10.1002/cpp.2157

Hitchcock, C., Ellis, A. A., Williamson, P., \& Nixon, R. D. V. (2015). The Prospective Role of Cognitive Appraisals and Social Support in Predicting Children's Posttraumatic Stress. Journal of Abnormal Child Psychology. https://doi.org/10.1007/s10802-015-0034-7

Keeping, L. M., \& Levy, P. E. (2000). Performance appraisal reactions: Measurement, modeling, and method bias. Journal of Applied Psychology. https://doi.org/10.1037/0021-9010.85.5.708

Kotera, Y., Van Laethem, M., \& Ohshima, R. (2020). Cross-cultural comparison of mental health between Japanese and Dutch workers: relationships with mental health shame, self-compassion, work engagement and motivation. Cross Cultural \& Strategic Management, 27(3), 511-530. https://doi.org/10.1108/CCSM-02-2020-0055

Lazarus, R. S., \& Folkman, S. (1987). Transactional theory and research on emotions and coping. European Journal of Personality, 1(3), 141-169.

Lepine, J. A., Lepine, M. A., \& Jackson, C. L. (2004). Challenge and hindrance stress: Relationships with exhaustion, motivation to learn, and learning performance. In Journal of Applied Psychology. https://doi.org/10.1037/0021-9010.89.5.883

McGrath, J. E., \& Beehr, T. A. (1990). Time and the stress process: Some temporal issues in the conceptualization and measurement of stress. Stress Medicine, 6(2), 93-104. https://doi.org/10.1002/smi.2460060205

Neff, K. D. (2011). Self-compassion, self-esteem, and well-being. Social and Personality Psychology Compass. https://doi.org/10.1111/j.1751-9004.2010.00330.x

NEFF, K. D. (2003). The Development and Validation of a Scale to Measure Self-Compassion. Self and Identity. https://doi.org/10.1080/15298860309027

O’Brien, K. E., \& Beehr, T. A. (2019). So far, so good: Up to now, the challenge-hindrance 
framework describes a practical and accurate distinction. Journal of Organizational Behavior, 40(8), 962-972. https://doi.org/10.1002/job.2405

Parker, S. K., Morgeson, F. P., \& Johns, G. (2017). One hundred years of work design research: Looking back and looking forward. Journal of Applied Psychology, 102(3), 403-420. https://doi.org/10.1037/apl0000106

Pérula-de Torres, L.-A., Atalaya, J. C. V.-M., García-Campayo, J., Roldán-Villalobos, A., Magallón-Botaya, R., Bartolomé-Moreno, C., Moreno-Martos, H., Melús-Palazón, E., Liétor-Villajos, N., Valverde-Bolívar, F. J., Hachem-Salas, N., Rodríguez, L.-A., Navarro-Gil, M., Epstein, R., Cabezón-Crespo, A., \& Moreno, C. M.-V. (2019). Controlled clinical trial comparing the effectiveness of a mindfulness and self-compassion 4-session programme versus an 8 -session programme to reduce work stress and burnout in family and community medicine physicians and nurses: MINDUUDD study protocol. BMC Family Practice, 20(1), 24. https://doi.org/10.1186/s12875-019-0913-z

Podsakoff, P. M., MacKenzie, S. B., Lee, J.-Y., \& Podsakoff, N. P. (2003). Common method biases in behavioral research: A critical review of the literature and recommended remedies. Journal of Applied Psychology, 88(5), 879-903. https://doi.org/10.1037/0021-9010.88.5.879

Prem, R., Kubicek, B., Diestel, S., \& Korunka, C. (2016). Regulatory job stressors and their within-person relationships with ego depletion: The roles of state anxiety, self-control effort, and job autonomy. Journal of Vocational Behavior. https://doi.org/10.1016/j.jvb.2015.11.004

Prem, R., Ohly, S., Kubicek, B., \& Korunka, C. (2017). Thriving on challenge stressors? Exploring time pressure and learning demands as antecedents of thriving at work. Journal of Organizational Behavior, 38(1), 108-123. https://doi.org/10.1002/job.2115

Rivkin, W., Diestel, S., \& Schmidt, K. H. (2015). Affective commitment as a moderator of the adverse relationships between day-specific self-control demands and psychological well-being. Journal of Vocational Behavior. https://doi.org/10.1016/j.jvb.2015.03.005

Roseman, I. J., Wiest, C., \& Swartz, T. S. (1994). Phenomenology, Behaviors, and Goals Differentiate Discrete Emotions. Journal of Personality and Social Psychology. https://doi.org/10.1037/0022-3514.67.2.206

Schaufeli, W. B., \& Bakker, A. B. (2010). Defining and measuring work engagement: Bringing clarity to the concept. In Work Engagement: A Handbook of Essential Theory and Research. https://doi.org/10.4324/9780203853047

Schaufeli, W., Salanova, M., González-romá, V., \& Bakker, A. (2002). The Measurement of Engagement and Burnout: A Two Sample Confirmatory Factor Analytic Approach. Journal of Happiness Studies. https://doi.org/10.1023/A:1015630930326

Schmitt, A., Ohly, S., \& Kleespies, N. (2015). Time pressure promotes work engagement. Journal of Personnel Psychology, 14(1), 28-36.

Schwarz, N., \& Clore, G. L. (2006). Feelings and Phenomenal Experiences. In Social Psychology. Handbook of basic principles. 


\section{Macrothink}

International Journal of Human Resource Studies

ISSN 2162-3058

2020, Vol. 10, No. 4

Tadić, M., Bakker, A. B., \& Oerlemans, W. G. M. (2015). Challenge versus hindrance job demands and well-being: A diary study on the moderating role of job resources. Journal of $\begin{array}{llll}\text { Occupational and Organizational } & \text { Psychology, } & \text { 88(4), }\end{array}$ https://doi.org/10.1111/joop.12094

Ten Brummelhuis, L. L., \& Bakker, A. B. (2012). Staying engaged during the week: The effect of off-job activities on next day work engagement. Journal of Occupational Health Psychology, 17(4), 445-455.

Vötter, B., \& Schnell, T. (2019). Cross-Lagged Analyses Between Life Meaning, Self-Compassion, and Subjective Well-being Among Gifted Adults. Mindfulness, 10(7), 1294-1303. https://doi.org/10.1007/s12671-018-1078-x

Webster, J. R., Beehr, T. A., \& Love, K. (2011). Extending the challenge-hindrance model of occupational stress: The role of appraisal. Journal of Vocational Behavior, 79(2), 505-516. https://doi.org/10.1016/j.jvb.2011.02.001

\section{Appendix}

Table 1. Mean, standard deviations, correlation, and reliability analysis

\begin{tabular}{lrrrrrrrrr}
\hline & $\boldsymbol{M}$ & $\boldsymbol{S D}$ & $\mathbf{1}$ & $\mathbf{2}$ & $\mathbf{3}$ & $\mathbf{4}$ & $\mathbf{5}$ & $\mathbf{6}$ & $\mathbf{7}$ \\
\hline 1. Gender & 1.32 & .46 & 1 & & & & & & \\
2. Age & 1.16 & .47 & -.03 & 1 & & & & & \\
3. Tenure & 2.07 & .82 & .02 & $.29^{* *}$ & 1 & & & & \\
4. Work engagement & 3.88 & 1.75 & .12 & .00 & .00 & $\mathbf{( 0 . 9 5 )}$ & & & \\
5. Negative affect & 3.29 & 1.06 & .06 & -.02 & .02 & $.17^{*}$ & $(\mathbf{0 . 8 5})$ & & \\
6. Self-compassion & 3.72 & 1.49 & -.01 & .01 & $.20^{*}$ & $.16^{*}$ & $.21^{*}$ & $(\mathbf{0 . 9 0 )}$ & \\
7. Challenge stress & 3.21 & 1.26 & .05 & .04 & $.22^{* *}$ & $-.16^{*}$ & $.17^{*}$ & $.19^{*}$ & $(\mathbf{0 . 8 8})$ \\
\hline
\end{tabular}

Notes: $\mathrm{N}=137$.

$* \mathrm{p}<0.05 ; \quad * * \mathrm{p}<0.01$.

Table 2. Negative affect as a mediator of challenge stress and work engagement

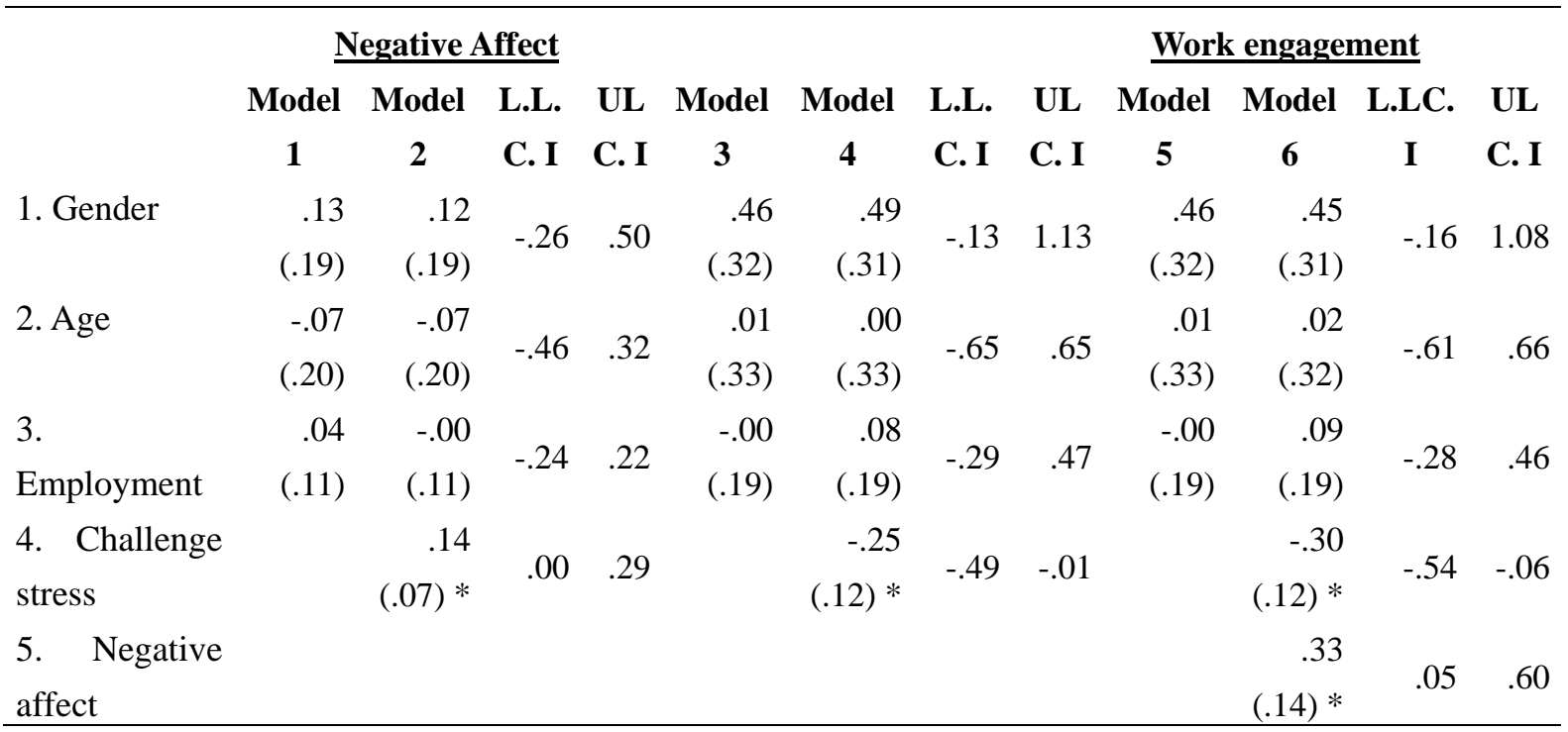




$\begin{array}{rrrrrrr}\mathrm{R}^{2} & .006 & .053 & .015 & .015 & .015 & .015 \\ \Delta \mathrm{R}^{2} & .006 & .048 * & .048 * & .032 * & .062 * & .042 *\end{array}$

Notes: $\mathrm{N}=137$.

$* \mathrm{p}<0.05 ; * * \mathrm{p}<0.01 ; * * * \mathrm{p}<0.001$

Table 3. Results of the Moderating Effect of self-compassion

\section{$\underline{\text { Negative Affect }}$}

L.L. UL

\begin{tabular}{|c|c|c|c|c|c|}
\hline & Model 1 & Model 2 & Model 3 & C. I & C. I \\
\hline 1. Gender & $.13(.19)$ & $.14(.19)$ & $.07(.19)$ & -.30 & .45 \\
\hline 2. Age & $-.07(.20)$ & $-.05(.19)$ & $-.00(.19)$ & -.39 & .38 \\
\hline 3. Employment & $.04(.11)$ & $-.03(.12)$ & $-.04(.12)$ & -.28 & .19 \\
\hline 4. Challenge stress (CS) & & $.01(.08)$ & $.00(.08)$ & -.15 & .16 \\
\hline 5. Self-compassion (SEC) & & $.17(.06) * *$ & $.14(.06) *$ & .02 & .27 \\
\hline CS x SEC & & & $-.09(.04) *$ & -.19 & -.00 \\
\hline $\mathrm{R}^{2}$ & .006 & $.060 * *$ & $.095 * *$ & & \\
\hline$\Delta \mathrm{R}^{2}$ & .006 & $.065 * *$ & $.025 * *$ & & \\
\hline
\end{tabular}

Notes: 137.

$* \mathrm{p}<0.05 ; * * \mathrm{p}<0.01 ; * * * \mathrm{p}<0.001$

Table 4. Results of the Moderated Path Analysis

\begin{tabular}{lccc}
\hline \multicolumn{1}{c}{ Moderator } & \multicolumn{3}{c}{ Challenge stress (X) $\rightarrow$ Negative } \\
& affect $(\mathbf{M}) \rightarrow$ Work engagement (Y) \\
\hline & Indirect & Boot SE & $95 \%$ C.I \\
& Effects & & \\
Low levels of self compassion (-1 SD) & .07 & .05 & {$[.024, .048]$} \\
Mean levels of self compassion & -.00 & .04 & {$[.056, .407]$} \\
High levels of self compassion (+1 SD) & -.04 & .06 & {$[-.387, .457]$} \\
\hline
\end{tabular}

Notes: $\mathrm{n}=137$. Bootstrap $\mathrm{N}=10,000$.

$P_{M X}$-Path from challenge stress to employee negative affect;

$P_{Y M}$ - Path from negative affect to work engagement; 
$P_{Y X}$ - Path from challenge stress to work engagement.

$* \mathrm{p}<0.05, * * \mathrm{p}<0.01$.

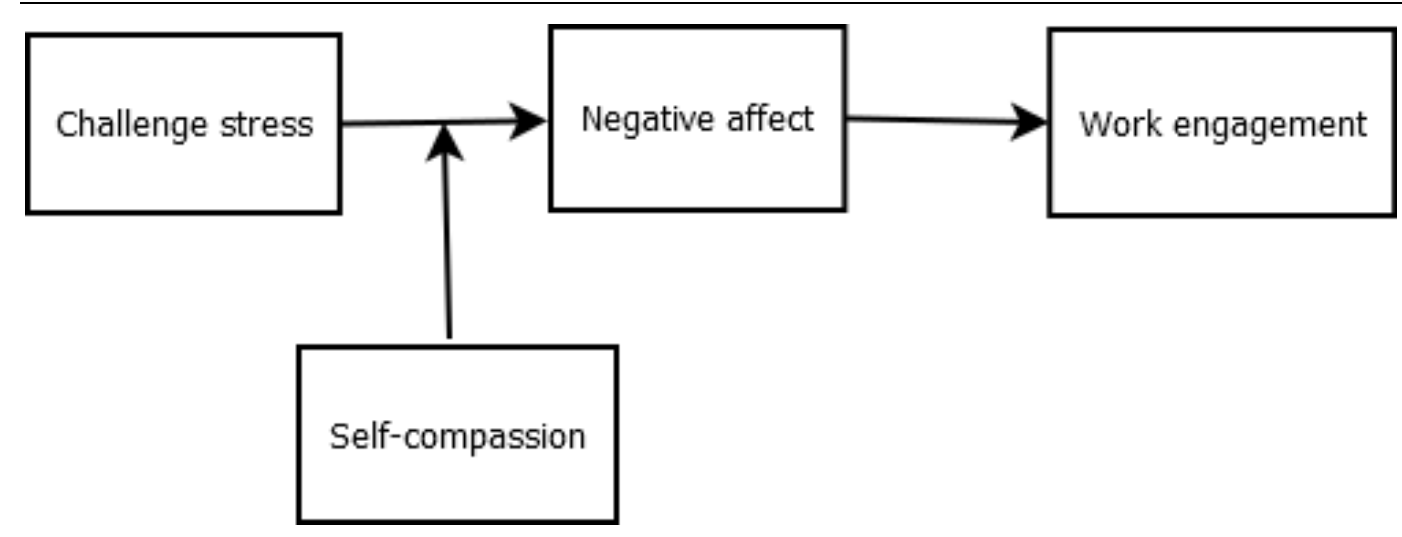

Figure 1. The hypothesized model

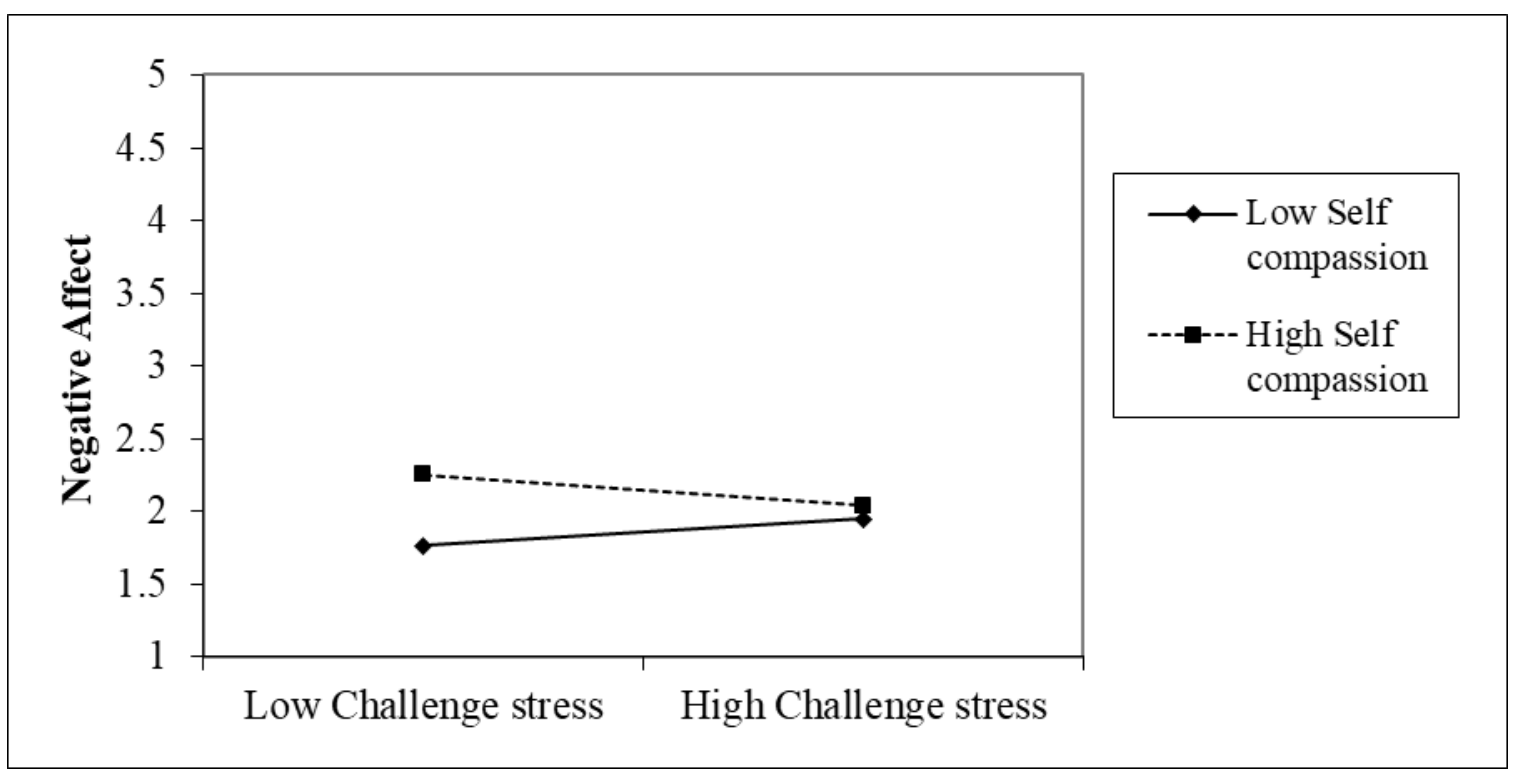

Figure 2. The moderating effect of self-compassion on the relationship between challenge stress and negative affect

\section{Copyright Disclaimer}

Copyright for this article is retained by the author(s), with first publication rights granted to the journal.

This is an open-access article distributed under the terms and conditions of the Creative Commons Attribution license (http://creativecommons.org/licenses/by/4.0/). 